\title{
Factors That Influence Persistence in Science and Engineering Career Aspirations
}

Wei-Cheng Mau

The author investigated students' persistence regarding career aspirations in science and engineering (SE) professional careers as a function of race and sex. In a nationally representative sample of 8th graders, persistent racial minority and female students were compared with nonpersistent racial minority and male students regarding their self-concept, parental involvement, socioeconomic status, and academic achievement. Men were more likely than women to persist in SE career aspirations. Persistent students scored higher than did nonpersistent students on all of the variables studied. Academic proficiency and math self-efficacy were 2 of the strongest predictors of persistence in SE careers.

Women and minorities are entering male-dominated careers in increasing numbers and at a rapid pace. This fact has prompted numerous researchers to study the characteristics of women who engage in nontraditional careers (e.g.,Anderson, 1992; Grandy, 1992; Hill, 1999; Huang, Taddese, Walter, \& Peng, 2000; Lips, 1992; Mau, Domnick, \& Ellsworth, 1995; Oakes, 1990; Seymour, 1995). However, most of these studies have concentrated on the nontraditional career choices of college and adult populations. Moreover, most of these studies provide no information on the significance of each variable in comparison with the others, nor do they indicate how these variables interrelate and contribute to the choices women make when choosing nontraditional careers.

Because of the critical nature of students' educational aspirations, research-ers ( e.g., Anderson, 1992; Farmer, Wardrop, Anderson, \& Risinger, 1995; Fouad \& Smith, 1996; Hanson, 1994; Mau, 1995; Mau \& Bikos, 2000; Mau et al., 1995; Wilson \& Wilson, 1992) have begun investigating the relative importance of factors that have been theorized as being influential in shaping those specific aspirations. For example, Mau et al. ( 1995) compared eighth-grade female students who aspired to science and engineering careers with those who aspired to homemaking careers. Their results showed that students who aspired to nontraditional careers had higher academic achievement, self-esteem, internal locus of control, parental expectations, and socio-economic status. Informed by social cognitive career theory (Lent, Brown, \& Hackett, 1996 ), Mau and Bikos ( 2000) identified four clusters of variables-personal/psychological characteristics, family variables, school experiences, and race and sex-that significantly predicted the occupational aspirations of racial minority and female students.

Social cognitive career theory (SCCT) has emerged as an influential theory in describing an individual's career development (Isaacson \& Brown, 2000). According to the SCCT (Lent et al., 1996), in addition to genetically determined characteristics, career-related behavior is influenced by four variables-behaviors, self-efficacy beliefs, outcome ex-pectations, and goals. Selfefficacy serves as a generative mechanism through which individuals integrate and apply their existing cognitive, behavioral, and social skills to a task. SCCT posits that self-efficacy affects thought patterns and partly determines individuals' actions: their decisions to engage in a task, to put forth effort, and to persevere under failure (Bandura, 1986 ). In this study, I used the SCCT as a conceptual framework for understanding how students attain varying levels of performance and "persistence in their educational and career pursuit" (Lent \& Brown, 1996, p. 311).

Although longitudinal studies (Farmer et al., 1995; Ginorio, Brown, Henderson, \& Cook, 1993; Meinster \& Rose, 2001) have indicated that students' interest in science and math decreases over time, studies concerning the factors associated with persistence in aspiring to SE-related careers of women and 
minorities are very limited. I used a nationally representative sample of eighth-grade students to investigate persistence of participants' SE career aspirations as a function of race and sex. I identified participants who indicated in the eighth grade that they aspired to SE careers and persisted for 6 years in the same career aspirations. Differences in race and sex, as well as the variables previously identified as important in predicting occupational attainment, were also examined. Specifically, persistent racial minority and female students were com-pared with nonpersistent racial minority and male students with regard to their self-concept, parental expectations and educational involvement, socioeconomic status, and academic achievement. I used a logistic regression model to determine the relative importance of these variables in explaining persistence in SE aspirations. The following specific hypotheses were investigated.

Hypothesis 1: Sex differences exist in an individual's persistence in SE aspirations.

Hypothesis 2: Racial differences exist in persistence in SE aspirations. Hypothesis 3: There are differences between persisters and switchers in

self-efficacy, academic achievement, socioeconomic status, and paren-tal expectation.

Hypothesis 4: There are unique contributions of sex and race in predicting

persistence in SE aspirations.

Today's adolescents will join a workforce whose demographics are undergoing rapid change. The increasingly diverse workforce and the competitive job market mean that an understanding of career aspirations and persistence of the major contributing workforce becomes critical. Understanding racial and sex differences in persistence of career aspirations would allow counselors and school administrators to take a proactive approach to tailoring developmentally appropriate and culturally sensitive career interventions for individuals who represent diverse cultural backgrounds. Unlike some career fields, preparation for nontraditional careers, especially in the areas of science and engineering, must begin early. Training in math and science needs to be sequential and uninterrupted from elementary school through high school, and fundamentals must be mastered before high school (Smith, 1980). Knowledge of the factors that are related to persistence in SE-related careers should be useful to counselors in middle schools, high schools, and colleges in de-signing interventions that will lead to greater persistence of women and racial minorities in this career pipeline.

\section{Method}

\section{Sample}

The data were based on the National Educational Longitudinal Survey of 1988 (NELS: 88; see National Center for Educational Statistics [NCES], 1990), which consisted of base year, first follow-up, second follow-up, and third follow-up longitudinal survey data. NELS:88 is the most recent series of longitudinal studies designed to "provide trend data about critical tran-sitions experienced by students as they leave elementary school and progress through high school and into college or their careers" (p. 5). The base year survey comprised a nationally representative sample of 24,599 students selected from 1,052 middle schools (public, $\mathrm{n}=815$; private, $\mathrm{n}=237$ ) in the United States. The sample was stratified by school size, urban versus rural, region, and percentage of minority populations (NCES, 1994). Because some students dropped out of the survey, the sample was re-freshed with additional students in both the first follow-up (10th grade, $N=20,840$ ) and second follow-up ( 12 th grade, $N=21,188$ ). The third follow-up took place in the spring of 1994, when most participants had been out of high school for 2 years. The third follow-up sample consisted of 14,915 participants. The sex and race breakdowns were 7,565 girls and 7,350 boys and 9,919 White Americans, 2,017 African Americans, 1,680 Hispanic Americans, 1,087 Asian Americans, and 212 Native Americans, respectively. Due to the oversampling of Hispanic and Asian Pacific Islander 
students, sample weights were used to reduce the over sampling bias. Because of sample refreshing, NELS:88 comprised a nationally representative sample of spring-term 1990 sophomores and spring-term 1992 seniors. Of the 14,915 participants surveyed in 1994, 55.5\% enrolled in the postsecondary institutions as full-time students, $9.5 \%$ enrolled as part-time students, and $35 \%$ did not enroll in a postsecondary institution.

\section{Variables}

Dependent variables. Persistence in SE career aspirations was measured by the following survey question, which was administered to eighth graders: "Which occupation do you expect or plan to have when you are 30 years old?" Responses to SE professional careers were identified and compared with the responses by the same individuals who responded to the question at three different times during a 6-year period.

Independent variables. Four clusters of independent variables were included:

1. Psychological: self-esteem (seven items, e.g., "I feel good about myself"), locus of control (six items, e.g., "I don't have enough control over the direction my life is taking"), and academic selfefficacy (four items, e.g., "Math is one of my best subjects" "English is one of my best subjects").

2. Family: perceived parental expectations, socioeconomic status (i.e., a composite score of parent's education, occupation, and family income), parental school involvement (seven items, e.g., how often students have discussed selecting school courses or programs with parents), parental academic involvement (four items, e.g., how of-ten parents attend school meetings), and number of siblings.

3. School: academic proficiency (measured by a composite score of a 21-item reading and a 40-item math proficiency test developed by the Educational Testing Service), academic program (general, academic, and vocational/technical program), school setting (urban, suburban, rural), school size, and school type (public or private/parochial schools). With the exception of academic proficiency, all school variables were coded as dummy variables.

4. Sex and race: Both sex and race were entered as dummy variables.

Detailed psychometric information about these survey questions can be found in the NCES's (1991) psychometric report for the NELS:88 base year test battery.

\section{Data Analysis}

Because of the dichotomous nature of the dependent variables, logistic regression models were used. Logistic regression analysis has a number of advantages over other multivariate techniques ( e.g., discriminant or multiple regression analyses) because it permits violation of normality, and it is interpretable in terms of probability (Cizek \& Fitzgerald, 1999). Logistic analyses were conducted to identify variables that would predict (a) students who aspired to SE occupations in the eighth grade and per-sisted 2 years beyond high school and (b) students who aspired to SE occupations in the eighth grade but did not persist 2 years beyond high school. As stated previously, the variable selection and entry into the model were guided by the SCCT. Predictors were entered in blocks using a forward stepwise method, with school variables entered first, followed by family variables, psychological variables, and sex and race. The analyses were based on weighted samples that were created to adjust for the over sampling bias, and the observations were redistributed to represent the distribution in the population (NCES, 1997). This was done by averaging the first-third follow-up panel weights (f3pnlwt). Design effects were also used to adjust standard error for hypothesis testing. Sex differences in the predictors for persistence in SE were analyzed using a 2 (persistence) $\times 2$ (sex) multivariate analysis of variance. 


\section{Results}

To understand race and sex differences in the persistence of SE career aspirations, four hypotheses were tested: (a) Sex differences exist in an individual's persistence in SE aspirations; ( b) racial differences exist in persistence in SE aspirations; (c) there are differences between persisters and switchers in selfefficacy, academic achievement, socioeconomic status, and parental expectation; and (d) there are unique contributions of sex and race in predicting persistence in SE aspirations. Of the initial 24,599 eighth-grade students, 827 students aspired to SE careers. Of the 827 students, 176 continued with the same aspirations in SE 6 years after they had been identified (persisters), whereas 583 changed their aspirations to non-SE careers (switchers). Sixty-eight dropped out of school.

I conducted chi-square analyses to test Hypotheses 1 and 2 . Results showed significant differences in SE persistence as a function of $\operatorname{sex}\left(X^{2}=17.01, p<.000\right)$. As indicated in Table 1, of the 827 eighth-grade students who aspired to SE careers, only $22 \%$ retained their SE aspirations 6 years later. Male participants $(26.5 \%)$ were more likely than female participants (12.1\%) to persist in their SE career aspirations. Chisquare analysis did not show a significant difference as a function of race $\left(X^{2}=4.93, p<.177\right)$.

In order to test Hypothesis 3, a multivariate analysis of variance was conducted to compare persisters and switchers on selected variables. Re-sults showed a significant difference for persistence, $F(9,413)=4.22, p<.000$. No significant sex differences or interaction (Persistence $x$ Sex) were found. Table 2 provides means and standard deviations of the selected variables by persistence and sex. Ad hoc analyses indicated significant differences in academic proficiency, $F(1,421)=5.40, p<.021$; socio-economic status, $F(1,421)=5.32, p<.022$; parental expectations, $F(1,421)=4.99, p<.026$; math self-efficacy, $F(\mathrm{l}, 421)=29.80, p<.000$; and reading self-efficacy, $F(1,421)=22.43, p<.000$. On all of these variables, persisters scored significantly higher than switchers.

A logistic regression analysis was conducted to examine Hypothesis 4 . Results showed significant improvement in the fit of the model when the school $\left(X^{2}=4.34, p<.83, R^{2}=.043\right)$ and psychological variables $\left(X^{2}=9.51, p<.30, R^{2}=.159\right)$ were added. Of special interest were the effects of sex and race, which were entered last in the model. Significant improvement was found after their addition $\left(X^{2}=9.20\right.$, $\mathrm{p}<.33, R^{2}=.227$ ). The beta coefficient value in the logistic regression table (see Table 3 ) represents the change in log odds of the dependent variable occurring related to one unit change in the predictor or independent variable, with other variables held constant. The greater the beta value, the more the predictor is weighted in the model. As can be seen in Table 3, academic proficiency and math self-efficacy were among the better predictors of SE persistence than sex was. Other factors being equal, male students' likelihood of remaining in the pipeline in the same time span was greater than for female students. Holding other factors constant, Hispanic students were less likely than White students to retain their SE aspirations. The predictive ability of the model is estimated through the probability of classification of respondents. This model had a correct classification rate of $77 \%$.

TABLE 1

Percentage of Students Who Aspired to Science and Engineering Careers by Sex and Race $(n=827)$

\begin{tabular}{lcccccc}
\hline & \multicolumn{6}{c}{ Percentage } \\
\cline { 2 - 7 } Variable & Boys & Girls & Asian & Black & Hispanic & White \\
\hline Total & 12.5 & 4.8 & 13.1 & 6.0 & 7.5 & 8.6 \\
Switchers & 73.5 & 87.9 & 64.7 & 81.7 & 74.1 & 79.2 \\
Persisters & 26.5 & 12.1 & 35.3 & 18.3 & 25.9 & 20.8 \\
\hline
\end{tabular}

Note. Of the 827 eighth-grade students who aspired to SE careers, $176(22 \%)$ retained their SE aspirations 6 years later. 
TABLE 2

Means and Standard Deviations of Selected Variables Comparing Science and Engineering Aspiration Persistence by Sex

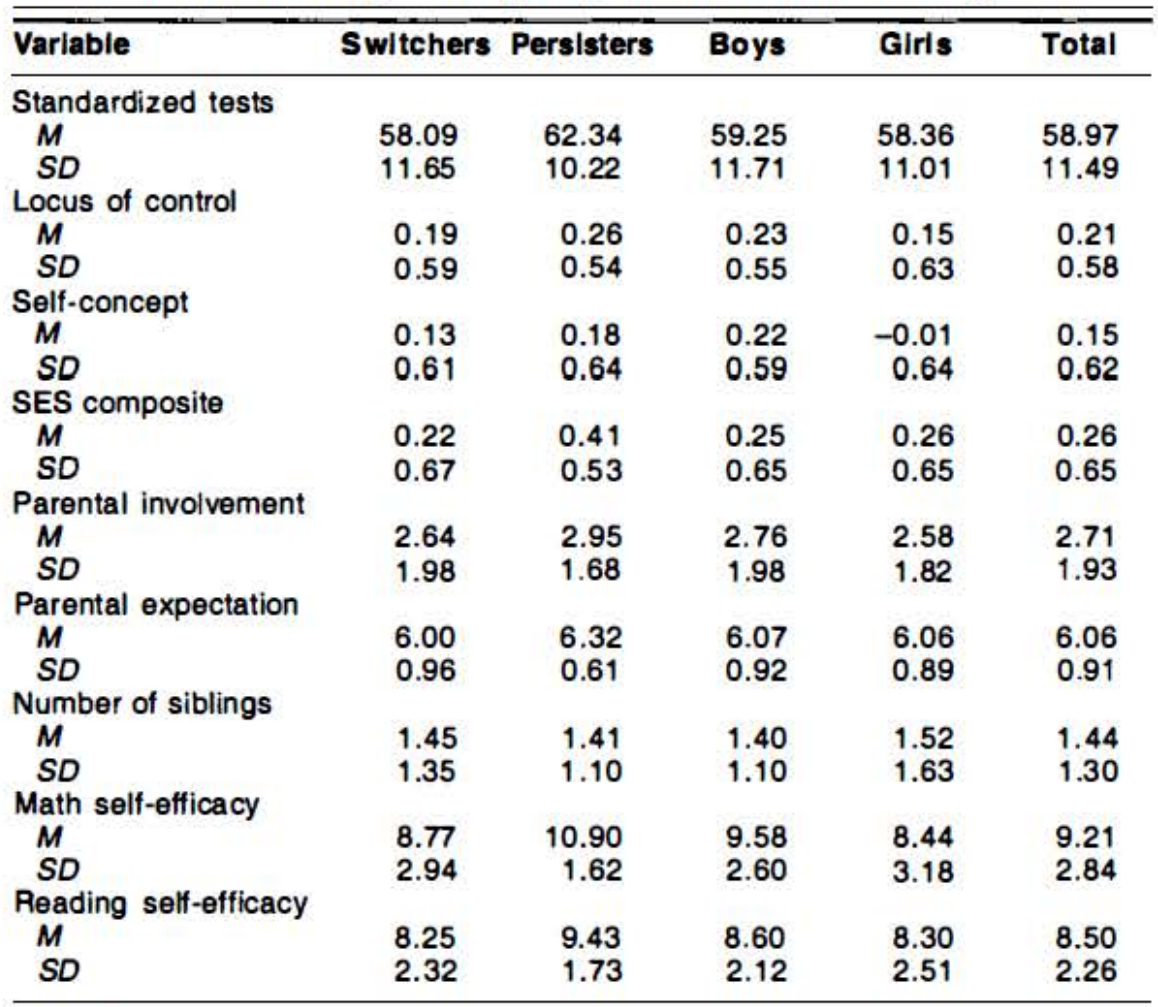

Note. SES $=$ socioeconomic status.

TABLE 3

Hierarchical Multiple Regression Predictors of Persistent Aspirations in Science and Engineering Careers $(n=790)$

\begin{tabular}{lrcrcc}
\hline \hline Varlable & \multicolumn{1}{c}{$\boldsymbol{B}$} & $\boldsymbol{d}$ & Wald & $\boldsymbol{p}$ & Exp (B) \\
\hline Academic proficiency & 0.030 & 1 & 6.44 & .011 & 1.03 \\
Self-concept & -0.171 & 1 & 0.49 & .485 & 0.84 \\
Locus of control & -0.081 & 1 & 0.08 & .781 & 0.92 \\
Math self-efficacy & 0.286 & 1 & 15.00 & .000 & 1.33 \\
English self-efficacy & 0.067 & 1 & 0.75 & .387 & 1.07 \\
Men & 1.077 & 1 & 11.26 & .001 & 2.94 \\
Race & & 3 & 10.62 & .014 & \\
Asian & 0.717 & 1 & 2.39 & .122 & 2.05 \\
Hispanic & -0.453 & 1 & 0.53 & .468 & 0.64 \\
Black & 1.576 & 1 & 7.61 & .006 & 4.84 \\
\hline
\end{tabular}

Note. Variables were entered in blocks using the forward stepwise method. 


\section{Discussion}

Four clusters of variables were used to predict students' persistence in career aspirations in SE professional careers. The SCCT (Lent et al., 1996) was used as a theoretical framework to guide the variable selection procedure. The unique contributions of race and sex were of particular interest in this study. The role of self-efficacy in the prediction model was also examined in light of the SCCT. These results provide support for the SCCT. The results of this study indicated that before adding race and sex to the SCCT model, academic proficiency and math self-efficacy were the two most predictive variables in SE career persistence. It is interesting that academic proficiency was the only significant predictor among the school variables. Variables previously identified as important in explaining differences in nontraditional career aspirations, such as parental expectations/ school involvement and the academic program, had minimal predictive power (Mau et al., 1995). It seems that these variables were more effective for identifying students who aspired to nontraditional careers but were less effective in explaining persistence in SE aspirations. Although academic proficiency is a significant predictor for persistence in SE aspirations, it is less predictive than math self-efficacy (i.e., the way students think about the quantitative subjects). As shown in other studies (e.g., Eccles, 1994), math self-efficacy seems to be the most predictive variable for persistence in SE aspirations. This finding lends strong support to the SCCT because contextual, experiential, and learning factors were mediated by the self-efficacy beliefs that predicted career goal outcomes.

Unexpectedly, none of the family variables had a significant impact on persistence in SE career aspirations. Although there were significant differences between persisters and switchers regarding parental expectations and socioeconomic status, these variables were less potent in predicting SE persistence than academic proficiency and math self-efficacy. Their unique contribution diminished when other variables were added to the model. This finding, however, is consistent with the findings of Farmer et al. (1995). When all of the factors were combined, perhaps the most comprehensive model that explains persistence of career aspiration can be attributed to the work of Lent, Brown, and Hackett (2000). In their SCCT, Lent et al. (2000) explained how contextual support and personal input affect self-efficacy expectations, which, in turn, translates into career interests and career goals. In other words, if people perceive their efforts to be impeded by adverse environmental factors, such as inadequate support systems or an intimidating environment, their aspirations are less likely to be translated into goals and, thus, less likely for those goals to be translated into action.

What was the career status of women and minorities 6 years after they left the eighth grade? Similar to previous studies (Jacobs, 1987; Seymour, 1995), the current study showed that young women were less likely than men to persist in aspiring to SE careers. In addition to academic proficiency and math self-efficacy, several studies have pointed out that women tend to face tougher institutional and cultural barriers than their male counterparts do. For example, sex role stereotyping may affect the survival rate of women in the pipeline. Seymour (1995) argued that women may be concerned that if they are accepted by their male peers, they may lose their femininity. They may also have to deal with discriminatory hostility from some faculty members and from male students (Stafford, 1991). For adolescent women, the pressures of trying to balance current and future gender relations in an environment that challenges conventional norms for women creates additional tensions and contradictions (McKinnon \& AholaSidaway, 1995). Other factors, such as lower teacher expectations (Anderson, 1992) and lack of role models (Dryler, 1998; Nauta \& Kokaly, 2001), may also explain the loss of women in the pipeline.

Overall, less than one fourth of the students who aspired to SE careers maintained SE aspirations 6 years later. The eighth-grade students in the current study were in their early teens when they began to explore their career direction. It is not surprising that the majority of them changed their career goals when they encountered reality. Clearly, doing well academically was an important factor that helped persisters stay on the SE track. It is possible that other factors identified in this study may have led individuals toward the opposite direction and, thus, toward not envisioning SE careers as their ideal 
choices. Considering that there was a smaller percentage of women than men who persisted in SE aspirations, it seems important that the factors identified in this study be incorporated into intervention programs that would assist students in persisting and eventually prevailing in SE careers.

The implications of this study are dear: Achievement and confidence are key factors regarding persistence in SE career aspirations. Parents, teachers, and counselors must be aware of how their expectations and attitudes affect the math and science achievement of their students and, in turn, affect their students' vocational interests. Counselors could identify students who have SE aspirations but lack academic proficiency and help the students to develop strategies for achieving their own goals (Mau \& Bikos, 2000). It seems that programs designed to encourage adolescent girls to enroll in SE-related courses need to be sensitive to the intimidation and subtle pressures that young women may face. Bright young women and underrepresented minorities simply cannot be recruited into the SE pipeline without continued support and encouragement. Informal support groups may be helpful in addressing the problems of young women and racial minority students who are enrolled in nontraditional programs or course work. Strengthening support systems and eliminating barriers may be the most effective ways to encourage students to persist in efforts to achieve their career goals (Lent \& Brown, 1996).

Given the importance of self-efficacy, it is crucial for career counselors to develop interventions that build minority and female students' confidence and increase their self-understanding. Betz (1992) suggested the following interventions to increase efficacy expectations: structuring performance accomplishments, providing observational learning, teaching anxiety management, and providing verbal persuasion and encouragement. A career development program developed by O'Brien, Bikos, Flores, Dukstein, and Kamatuka (1996), based on the SCCT, has been shown to be promising in enhancing students' confidence in performing tasks that are related to investigating, selecting, and implementing a career choice. Counselors could use SCCT to design intervention programs that address school, family, and psychological issues. Recognition of the relationship among these factors can aid counselors as they develop programs and plan interventions for their students. Given the unique contribution of sex and race factors in predicting SE persistence, counselors should take a proactive approach to tailoring developmentally appropriate and culturally sensitive career interventions for individuals from diverse cultural backgrounds.

As is true of any study that uses general broad-based survey data, the current study is limited to the survey questions available in the questionnaire. For example, because an appropriate measure of selfefficacy was not available, I used locus of control and self-esteem to represent the self-efficacy construct. In addition, some data analyses were based on one-item responses only. Thus, special attention needs to be given to the interpretation of the results. More research is needed that focuses on factors influencing women's and racial minorities' persistence in SE aspirations. Further studies could include more rigorous calibrated measures. Given the predictive power of sex and race that was identified in this study, the next step in refining this line of research may be using structural equation modeling to examine sample specific models within a broader framework, such as SCCT. Knowledge generated from these kinds of research could further advance counseling practitioners' and researchers' understanding of career development of these underrepresented populations and factors that lead to persistence in participation in the SE workforce. 


\section{References}

Anderson, B. T. (1992). Minority females in the science pipeline: Activities to enhance readiness, recruitment, and retention. Initiatives, 55(3), 31-38.

Bandura, A. (1986). Social foundation of thought and action. Englewood Cliffs, NJ: Prentice Hall.

Betz, N. E. (1992). Counseling uses of career self-efficacy theory. The Career Development Quarterly, 41, 22-26.

Cizek, G. J., \& Fitzgerald, S. M. (1999). An introduction to logistic regression. Measurement and Evaluation in Counseling and Development, 31, 223-245.

Dryler, H. (1998). Parental role models, gender and choice. British Journal of Sociology, 49, 195-209.

Eccles, J. (1994). Understanding women's educational and occupational choices. Psychology of Women Quarterly, 18, 585-609.

Farmer, H.S., Wardrop, J. L., Anderson, M.Z., \& Risinger, R. (1995). Women's career choices: Focus on science, math, and technology careers. Journal of Counseling Psychology, 42, 155-170.

Fouad, N. A., \& Smith, P. L. (1996). A test of a social model for middle school students: Math and science. Journal of Counseling Psychology, 43, 338-346.

Ginorio, A. B., Brown, M. D., Henderson, R. S., \& Cook, N. (1993). Patterns of persistence and attrition among science and engineering majors at the University of Washington, 1985-1991. Seattle: University of Washington.

Grandy, J. (1992). Gender and ethnic differences among science and engineering majors: Experiences, achievements, and expectations (GRE Board Research Report No. 92-03R). (Document Reproduction Service No. ED388502)

Hanson, S. L. (1994). Lost talent: Unrealized educational aspirations and expectations among U.S. Youths. Sociology of Education, 67, 159-183.

Hill, S. (1999). Science and engineering degrees, by race/ethnicity of recipients: 1989-96 (NSF 99-332). Arlington, VA: National Science Foundation.

Huang, G., Taddese, N., Walter, E., \& Peng, S. S. (2000). Entry and persistence of women and minorities in college science and engineering education (Report No. NCES 2000-60 I). Washington, DC: U.S. Department of Education.

Issacson, L. E., \& Brown, D. (2000). Career information, career counseling, and career development ( $7^{\text {th }}$ ed.). Boston: Allyn \& Bacon.

Jacobs, J. (1987). The sex typing of aspirations and occupations: Instability during the careers of young women. Social Science Quarterly, 68, 122-137.

Lent, R. W., \& Brown, S. D. (1996). Social cognitive approach to career development: An overview. The Career Development Quarterly, 44, 310-321.

Lent, R. W., Brown, S. D., \& Hackett, G. (1996). Career development from a social- cognitive perspective. In D. Brown, L. Brooks, \& Associates (Eds.), Career choices and development (3rd ed., pp. 373-421). San Francisco: Jossey-Bass.

Lent, R. W., Brown, S. D., \& Hackett, G. (2000). Contextual supports and barriers to career choice: A social cognitive analysis.Journal of Counseling Psychology, 47, 36-49.

Lips, H. M. (1992). Gender- and science-related attitudes as predictors of college students' academic choices. Journal of Vocational Behavior, 40, 62-81.

Mau, W.-C. (1995).Educational planning and academic achievement of middle school students: A racial and cultural comparison.Journal of Counseling \& Development, 73, 518-526.

Mau, W.-C., \& Bikos, L. H. (2000). Educational and vocational aspirations of minority and female students: A longitudinal study. Journal of Counseling \& Development, 78, 186-194.

Mau, W.-C., Domnick, M,, \& Ellsworth, R. A. (1995). Characteristics of male students who aspire to science and engineering or homemaking occupations. The Career Development Quarterly, 43, 323-337.

Meinster, M. 0., \& Rose, K. C. (200/). Longitudinal influence of educational aspirations and romantic relationships on adolescent women's vocational interests. Journal of Vocational Behavior, 58, 313-327. 
McKinnon, M., \& Ahola-Sidaway, J. (1995). Workin' with the boys: A North American's perspective on non-traditional workinitiatives for adolescent females insecondary schools. Gender and Education, 7, 327-339.

National Center for Educational Statistics. (1990). National educational longitudinal study, 1988: Base year student component data file user's manual (Report No. 90-464, pp. 1-59). Washington, DC: U.S. Department of Education.

National Center for Educational Statistics. (1991). Psychometric report for the NELS:88: Base year test battery (Report No.91-468). Washington, DC: U.S. Department of Education.

National Center for Educational Statistics. (1994). National educational longitudinal study, 1988: Second followup: 1992 (Report No. 94-374, pp. 24-34). Washington, DC: U.S. Department of Education.

National Center for Educational Statistics. (1997). A note from the chief statistician: Technical approaches to performing regression and other multivariable techniques on NCES survey data (Notes No. 3). Washington, DC: U.S. Department of Education.

Nauta, M. M., \& Kokaly, M. L. (2001). Assessing role model influences on students' academic and vocational decision. Journal of Career Assessment, 9, 81-99.

Oakes, J.(1990). Opportunities, achievement, andchoice:Womenand minoritystudents in science and mathematics. Review of Research in Education, 16, 153-166.

O'Brien, K. M., Bikos, L. H., Flores, L. Y., Dukstein, R. D., \& Kamatuka, N. A. (1996, August). A career exploration programfor Upward Bound students. In K. M. O'Brien \& M. J. Heppner (Chairs), Future Directions in Career Counseling: Innovative interventions with special populations. Symposium conducted at the 1996 National Convention of the American Psychological Association, Toronto, Canada.

Seymour, E. (1995). The loss of women from science, mathematics, and engineering undergraduate majors: An explanatory account. Science Education, 79, 437-473.

Smith, E. J. (1980). Career development of minorities in nontraditional fields. Journal of Non-White Concerns, 8, 141-156.

Stafford, A. (1991). Trying work, gender, youth, and work experience. Edinburgh, UK: Edinburgh University Press.

Wilson, P. M., \& Wilson, J. R. (1992). Environmental influences on adolescent educational aspirations: A logistic transform model. Youth \& Society, 24, 52-70. 